\title{
Peresepan Obat Antihipertensi Dan Antidiabetik Oral Beserta Analisis Ketepatan Pada Pasien Lansia
}

\author{
Dewi Saraswati ${ }^{1,}$ Yuhansyah Nur Fauzi $i^{* *}$, Tri Fitri Yana Utami ${ }^{3}$ \\ 1, 2, 3 Program Studi S1 Farmasi STIKES Al-Irsyad Al-Islamiyyah Cilacap, Jawa Tengah, Indonesia \\ Email correspondence: "nur fauzi84@yahoo.co.id
}

\begin{abstract}
ABSTRAK
Program pengelolaan penyakit kronis (Prolanis) ditujukan kepada peserta usia diatas 60 tahun. Jenis penyakit yang termasuk dalam prolanis diantaranya hipertensi dan diabetes. Berdasarkan data Dinas Kesehatan (DINKES) Kabupaten Cilacap tahun 2018, hipertensi esensial menduduki urutan ke 5 dari 10 penyakit terbanyak dengan jumlah kasus hipertensi sebanyak 18.016 kasus. Jumlah kasus diabates melitus di Kabupaten Cilacap tahun 2018 sebanyak 4.806 kasus. Tujuan penelitian ini untuk mengatahui pola peresepan obat diabetes melitus dan obat hipertensi pasien lansia peserta prolanis, mengetahui obat-obat yang berpotensi menimbulkan ketidaktepatan bila digunakan pada lansia berdasarkan kriteria beers 2019. Metode yang digunakan dalam penelitian ini adalah metode deskriptif non analitik, data dikumpulkan secara retrospektif. Hasil penelitian menunjukan pola peresepan obat diabetes melitus oral yaitu metformin 47 resep (16,85\%), glimepirid 38 resep (13,62\%). Terapi kombinasi obat diabetes melitus yaitu metformin dengan glimepirid 136 resep (48,75\%). Pola peresepan obat hipertensi oral yaitu amlodipin 184 resep (66,95\%), Irbesartan 10 resep (3,58\%), captopril 10 resep (3,58\%). Terapi kombinasi terbanyak yaitu amlodipin dengan irbesartan sebanyak 18 resep (6,45\%). Hasil analisis berdasarkan kriteria beers 2019 yaitu glimepirid 221 resep (98,23\%), clonidin 2 resep (0,89\%), glibenklamid 1 resep (0,44\%) dan glimepirid dengan clonidin 1 resep $(0,44 \%)$.
\end{abstract}

Kata kunci: Prolanis, Pola Peresepan, Kriteria Beers 2019

\begin{abstract}
Chronic management program is aimed at participants aged over 60 years. Types of diseases hypertension and diabetes. Based on data from the public health Office of Cilacap Regency in 2018, essential hypertension ranks 5 out of 10 diseases with a total of 18,016 cases of hypertension. The number of cases of diabetes mellitus in Cilacap Regency in 2018 was 4,806 cases. This study aims to determine the pattern of prescribing diabetes mellitus drugs and hypertension drugs for elderly patients prolanis participants, knowing the drugs that have the potential to cause inaccuracies when used in the elderly based on beers 2019 criteria. The method used in this study is descriptive non-analytical, data collected retrospective. The results of this study showed that the prescription pattern for oral diabetes mellitus was 47 prescription, metformin (16.85\%), glimepirid 38 prescriptions $(13.62 \%)$. Combination therapy is metformin with glimepirid 136 prescriptions (48.75\%). The prescribing patterns of oral hypertension drugs 184 prescription amlodipine (66.95\%), 10 prescription Irbesartan (3.58\%), 10 prescription captopril (3.58\%). Combination therapy is amlodipine with irbesartan 18 prescription (6.45\%). The analysis on beers citeria 2019 , glimepirid 221 prescription $(98,23 \%)$, clonidin 2 prescription $(0,89 \%)$, glibenklamid 1 prescription $(0,44 \%)$ and glimepirid with clonidin 1 prescription $(0,44 \%)$.
\end{abstract}

Keywords: Prolanis, Prescribing Patterns, Beers Criteria 2019

\section{PENDAHULUAN}

Sejak tahun 2014 BPJS Kesehatan telah menerapkan Program Pengelolaan Penyakit Kronis (Prolanis). Prolanis ditujukan untuk pasien usia lanjut yang berumur diatas 60 tahun. Jenis penyakit yang yang termasuk dalam prolanis diantaranya hipertensi dan diabetes melitus [1]. Data Data dari Dinas Kesehatan (Dinkes) Kabupaten Cilacap tahun 2018 menyebutkan bahwa penyakit hipertensi esensial menduduki urutan penyakit terbanyak nomor lima dari 10 penyakit 
terbanyak dengan jumlah kasus hipertensi sebanyak 18.016 kasus. Kasus diabetes melitus di Kabupaten Cilacap tahun 2018 sebanyak 7.840 naik sangat tajam dibanding tahun 2017 hanya ada 4.806 kasus [2].

Berdasarkan golongan obat, yang paling banyak diresepkan adalah obat kardiovaskular sebanyak 30,61\%. Obat yang paling banyak diresepkan adalah amlodipin sebesar 3,95\% [3]. Evaluasi peresepan obat pada pasien geriatri sangat penting untuk dilakukan karena berkaitan dengan peningkatan morbiditas, kejadian yang tidak diinginkan terkait obat dan mortalitas. Penelitian tersebut menunjukan adanya reaksi obat yang tidak dinginkan pada pasien geriatri. Dari total 3.808 permintaan obat, $6 \%$ tergolong obat-obat yang tergolong potentially inappropriate medication (PIM) [4]. Kriteria beers merupakan salah satu kriteris eksplisit yang dapat mengidentifikasi potensi ketidaktepatan penggunaan obat pada pasien geriatri. Kelebihan dari kriteria beers yaitu penerapan sederhana, mudah diikuti, memiliki bukti yang kuat, dan murah [3].

Apotek Cahaya Husada Cilacap merupakan salah satu unit penyelenggara pelayanan kesehatan swasta yang memberikan pelayanan kesehatan kepada peserta Program Pengelolaan Penyakit Kronis (Prolanis) Program Rujuk Balik (PRB) dari berbagai Fasilitas Kesehatan Tahap Pertama (FKTP) di wilayah Cilacap kota yang melayani 12 fasilitas kesehatan (Faskes).

\section{METODE PENELITIAN}

\section{a. Metode Penelitian}

Metode yang digunakan dalam penelitian ini adalah metode deskriptif non-analitik, data dikumpulkan secara retrospektif. Populasi penelitian ini adalah pasien lansia peserta prolanis hipertensi dengan diabetes melitus yang mendapatkan resep dalam program rujuk balik di Apotek Cahaya Husada Cilacap. Subjek penelitan dalam penelitian ini sebanyak 279 peserta berasal dari jumlah total kehadiran di 6 bulan pada tahun 2019 .

b. Tempat dan Waktu Penelitian

Penelitian ini dilakukan di Apotek Cahaya Husada Cilacap, data yang diambil dari resep di bulan Januari-Februari 2019, Juni-Juli 2019, dan November-Desember 2019. Waktu penelitian dilaksanakan pada bulan April - Mei 2020.

c. Teknik dan Pengumpulan Data

Pengumpulan data yang dilakukan dengan menggunakan data peresepan obat yang ada di Apotek Cahaya Husada Cilacap.

\section{d. Analisis Data}

Analisis data dilakukan dengan menggunakan kriteria beers untuk ke tahap penyusunan hasil penelitian. Pola pengunaan obat dianalisis secara deskriptif untuk melihat persentase jumlah obat, persentase penggunaan obat. umur, dan persentase jenis kelamin pasien.

\section{HASIL DAN PEMBAHASAN}

Pengambilan data berasal dari resep dengan diagnosa hipertensi disertai diabetes melitus pada bulan Januari-Februari 2019, Juni-Juli 2019 dan November-Desember 2019. Penelitian dilakukan pada bulan April-Mei 2020 di Apotek Cahaya Husada Cilacap. Jumlah resep yang didapatkan berdasarkan kriteria inkusi sejumlah 279 resep, data yang terkumpul berupa data deskriptif. Penelitian ini sudah mendapatkan izin dari Komisi Etik Penelitian Kesehatan Fakultas Kedokteran Unsoed dengan No. Ref: 113/KEPK./IV/2020. 


\section{a. Karakteristik Pasien}

\section{Persentase Jumlah Pasien Berdasarkan Usia}

Usia lanjut merupakan usia diatas 60 tahun[1]. Usia lanjut terbagi beberapa kategori diantaranya usia lansia (60-74 tahun), usia tua (75-90 tahun) dan usia sangat tua (>90 tahun)[2] [6]. Dari 279 pasien, pasien berdasarkan usia terbanyak berada di rentang usia 60-74 tahun yaitu 257 pasien $(92 \%)$, rentang usia 75-90 tahun yaitu 22 pasien (8\%).

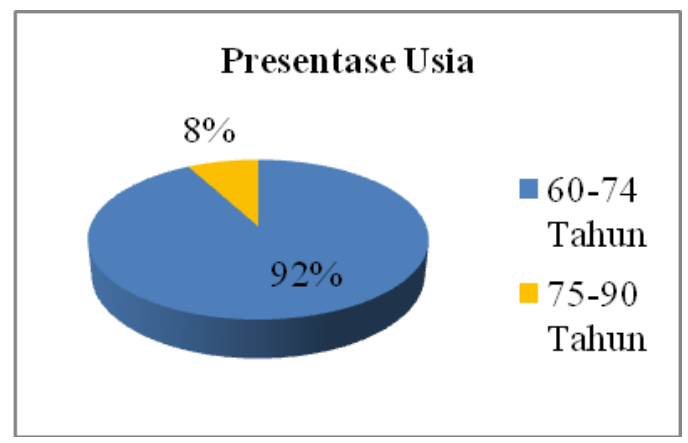

Gambar. 1 Presentase Usia

Peningkatan tekanan darah pada lansia disebabkan pola hidup yang kurang sehat pada saat muda [3]. Usia yang semakin bertambah, resiko terkena diabetes melitus meningkat berkaitan dengan ketidak seimbangan asupan makanan yang tinggi energi dengan pengeluaran energi, kurang aktivitas fisik dalam jangka waktu yang lama sehingga meningkatkan terjadinya obesitas[4].

\section{Persentase Jumlah Pasien Berdasarkan Jenis Kelamin}

Dari 279 pasien, jenis kelamin laki-laki sebanyak 107 pasien (38\%), sedangkan jenis kelamin perempuan sebanyak 172 pasien $(62 \%)$. Hasil penelitian menunjukkan jumlah jenis kelamin perempuan lebih banyak dibanding dengan jumlah jenis kelamin laki-laki.

Prevalensi hipertensi pada penderita diabetes mellitus lebih banyak dibandingkan dengan komorbit yang lainnya menunjukan jenis kelamin perempuan lebih banyak dibanding laki-laki sebanyak $63,41 \%$.[5]

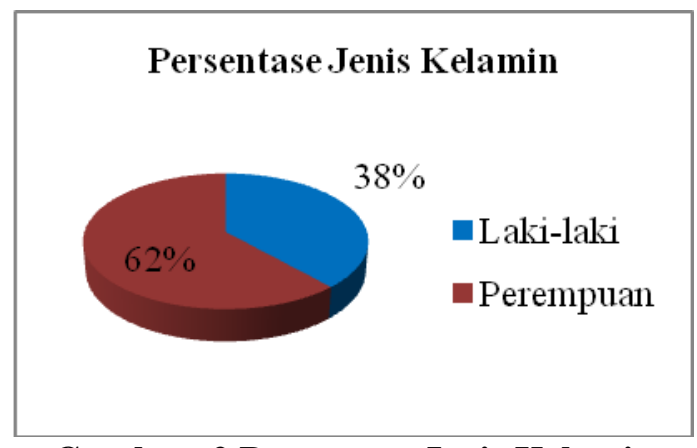

Gambar. 2 Presentase Jenis Kelamin

Menurut Wiharti et al. 2017, Hal ini disebabkan oleh faktor psikologis. Perempuan lebih sering menderita depresi dibanding laki-laki[5]. Pada penelitian Fitri et al, 2012, pada penderita diabetes melitus subyek penelitian berjenis kelamin perempuan sebanyak $63 \%$. Hal ini berkaitan dengan resiko berat badan lebih dan obesitas dibanding dengan laki-laki [6].

\section{B. Pola Peresepan Obat Hipertensi}

Pola peresepan obat hipertensi oral yaitu amlodipin 184 resep (66,95\%), Irbesartan 10 resep (3,58\%), captopril 10 resep $(3,58 \%)$. CCB digunakan untuk perawatan hipertensi termasuk amlodipin, yang bekerja dengan memblokir dan mengikat saluran kalsium yang ditemukan 
dipembuluh darah, sebagai hasil blokade saluran kalsium, CCB menyebabkan vasodilatasi (pelebaran) pembuluh darah[7].

Terapi kombinasi hipertensi terbanyak yaitu amlodipin dengan irbesartan sebanyak 18 resep (6,45\%). Penggunaan kombinasi CCB dengan ARB yang paling banyak dan efektif. Pengurangan tekanan darah tersebut terjadi karena ada edema parifer yang terjadi akibat penggunaan golongan $\mathrm{CCB}$ dan diatasi dengan penggunaan ARB sehingga kombinasi keduanya dianggap paling efektif dalam menurunkan tekanan darah tanpa efek samping[8].

Tabel. 1 Pola Peresepan Obat Hipertensi

\begin{tabular}{|c|c|c|}
\hline Jenis Obat & Jumlah R/ & Persentase \\
\hline \multicolumn{3}{|l|}{ Terapi Tunggal } \\
\hline Amlodipin & 184 & $66,95 \%$ \\
\hline Irbesartan & 10 & $3,58 \%$ \\
\hline Bisoprolol & 2 & $0,72 \%$ \\
\hline Captopril & 10 & $3.58 \%$ \\
\hline Ramipril & 2 & $0,72 \%$ \\
\hline Candesartan & 5 & $1,79 \%$ \\
\hline Telmisartan & 3 & $1,08 \%$ \\
\hline Clonidin & 1 & $0,36 \%$ \\
\hline \multicolumn{3}{|l|}{ Terapi Kombinasi } \\
\hline Amlodipin + ISDN & 2 & $0,71 \%$ \\
\hline Amlodipin + Diltiazem & 1 & $0,36 \%$ \\
\hline Amlodipin + Candesartan & 13 & $4,66 \%$ \\
\hline Amlodipin + Captopril & 1 & $0,36 \%$ \\
\hline Irbesartan + Amlodipin & 18 & $6,45 \%$ \\
\hline Irbesartan + Bisoprolol & 2 & $0,71 \%$ \\
\hline Bisoprolol + Furosemid & 2 & $0,71 \%$ \\
\hline Bisoprolol + Amlodipin & 1 & $0,36 \%$ \\
\hline Candesrtan + Bisoprolol & 1 & $0,36 \%$ \\
\hline Candesartan + Diltiazem & 1 & $0,36 \%$ \\
\hline Candesartan + Spironolakton & 1 & $0,36 \%$ \\
\hline Telmisartan + Amlodipin & 7 & $2,51 \%$ \\
\hline Spironolakton + Furosemid & 1 & $0,36 \%$ \\
\hline Jenis Obat & Jumlah R/ & Persentase \\
\hline Amlodipin + Diltiazem + Bisoprolol & 1 & $0,36 \%$ \\
\hline Amlodipin + Candesartan + Furosemid & 1 & $0,36 \%$ \\
\hline Amlodipin+ Bisoprolol+ Candesartan & 1 & $0,36 \%$ \\
\hline Clonidin+ Diltiazem+ Bisoprolol & 1 & $0,36 \%$ \\
\hline Amlodipin+ Candesartan+ Clonidin & 1 & $0,36 \%$ \\
\hline Amlodipin + Telmisartan+ Spironolakton & 1 & $0,36 \%$ \\
\hline Amlodipin + Bisoprolol +ISDN+ Telmisartan & 1 & $0,36 \%$ \\
\hline Amlodipin + Bisoprolol+ Spironolakton+ Furosemid & 1 & $0,36 \%$ \\
\hline Amlodipin + Candesartan+Furosemid + Spironolakton & 1 & $0,36 \%$ \\
\hline Amlodipin+ Bisoprolol+ ISDN+ Spironolakton+ Irbesartan & 1 & $0,36 \%$ \\
\hline $\begin{array}{l}\text { Amlodipin + furosemid+ Irbesartan + } \\
\text { Spironolakton+ISDN+Bisoprolol }\end{array}$ & 1 & $0,36 \%$ \\
\hline TOTAL & 279 & $100 \%$ \\
\hline
\end{tabular}

Keterangan :

$\%$ Peresepan Obat $=\underline{\text { Jumlah } R /} \times 100 \%$

Jumlah Total $R /$ 


\section{Pola Peresepan Obat Diabetes Melitus}

Hasil penelitian menunjukan pola peresepan obat diabetes melitus oral yaitu metformin 47 resep (16,85\%), glimepirid 38 resep (13,62\%). Menurut Septiyana dalam Misnadiarly 2006, metformin golongan biguanid merupakan jenis obat yang paling banyak digunakan dalam pengobatan diabetes mellitus tipe 2 pada pasien usia lanjut, jenis obat ini dianjurkan karena dapat menurunkan glukosa darah dengan memperbaiki transport glukosa kedalam sel otot yang dirangsang insulin, meningkatkan jumlah reseptor insulin. Glimepirid termasuk golongan sulfonilurea, sering disebut sebagai insulin secretagogues, yang bekerja merangsang sekresi insulin di sel beta langerhans[9].

Terapi kombinasi obat diabetes melitus terbanyak yaitu metformin dengan glimepirid 136 resep $(48,75 \%)$. Hal ini sejalan dengan penelitian Yuswantina,et al, 2018 yaitu jumlah terapi kombinasi sulfonilurea dengan biguanid (glimepirid dengan metformin) sebanyak 25 pasien dengan persentase sebesar 40,32\% [10].

Tabel. 2 Pola Peresepan Obat Diabetes Melitus

\begin{tabular}{llc}
\hline Jenis Obat & Jumlah R/ & Persentase \\
\hline Terapi Tunggal & & \\
\hline Metformin & 47 & $16,85 \%$ \\
Glimepirid & 38 & $13,62 \%$ \\
Gliquidon & 2 & $0,72 \%$ \\
Acarbose & 1 & $0,36 \%$ \\
\hline Terapi Kombinasi & & \\
\hline Glimepirid + Metformin & 136 & $48,75 \%$ \\
Glimepirid + Acarbose & 35 & $12,54 \%$ \\
Metformin + Acarbose & 2 & $0,72 \%$ \\
Pioglitazon + Acarbose & 1 & $0,36 \%$ \\
Pioglitazon + Metformin & 1 & $0,36 \%$ \\
Gliquidon + Acarbose & 1 & $0,36 \%$ \\
Glibenklamid + Metformin & 1 & $0,35 \%$ \\
Glimepirid + Metformin + Acarbose & 9 & $3,23 \%$ \\
Glimepirid + Pioglitazon+ Metformin & 4 & $1,43 \%$ \\
Glimepirid + Acarbose + Pioglitazon & 1 & $0,35 \%$ \\
\hline TOTAL & $\mathbf{2 7 9}$ & $\mathbf{1 0 0 \%}$ \\
\hline
\end{tabular}

\section{Keterangan :}

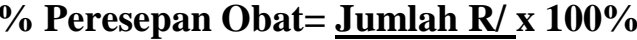

\section{Jumlah Total $\mathbf{R} /$}

\section{Obat Yang Perlu Mendapatkan Perhatian Bila Digunakan Pada Lansia \\ 1. Kriteria Beers}

Clonidin sebagai terapi lini pertama hipertensi pada lansia. Akan tetapi clonidin memiliki resiko tinggi yang berefek pada sistem saraf pusat (SSP) yang merugikan. Clonidin juga dapat menyebabkan bradikardi dan hipotensi ortotastik, hal tersebut menyebabkan clonidin tidak direkomendasikan sebagai pengobatan rutin untuk hipertensi [11].

Golongan sulfonilurea yaitu glimepirid dan glibenklamid, berdasarkan kriteria beers 2019, glimepirid dan glibenklamid memiliki waktu paruh yang lama jika digunakan pada lansia, dan dapat menyebabkan hipoglikemia yang berkepanjangan. Rekomendasi yang dianjurkan adalah menghindari penggunaan glimepirid sebagai pengobatan rutin pada lansia[11].

Rekomendasi yang dianjurkan adalah menghindari penggunaan glimepirid sebagai pengobatan rutin pada lansia. Hasil penelitian ini yang ditunjukan pada tabel 3, menunjukan glimepirid sebanyak 221 resep, dengan persentase $98,23 \%$, clonidin sebanyak 2 resep, dengan persentase $0,89 \%$, glibenklamid sebanyak 1 resep, dengan persentase $0,44 \%$ dan terapi kombinasi glimepirid dengan clonidin sebanyak 1 resep dengan persentase $0,44 \%$. 
Hasil analisis berdasarkan kriteria beers 2019 menunjukan bahwa perlunya perhatian dari tenaga kesehatan termasuk dokter dan farmasis dalam penggunaan clonidin, glibenklamid dan glimepirid terapi tunggal atau terapi kombinasi pada lansia[11].

Tabel. 3 Obat Yang Perlu Mendapatkan Perhatian Bila Digunakan Pada Lansia

\section{Keterangan : \\ \% Peresepan Obat $=$ Jumlah R/ $\mathbf{x} 100 \%$ \\ Jumlah Total $R /$}

\section{Peraturan Menteri Kesehatan No 67 Tahun 2015}

Efek samping obat perlu diwaspadai diantaranya captopril dapat mengakibatkan depresi, dan amlodipin dapat menyebabkan edema pada tungkai, bila digunakan untuk pengobatan jangka panjang[12]. Pada penelitian lain, penggunaan amlodipin dapat menyebabkan edema pada tungkai[13]. Hal ini sejalan dengan penelitian Baroroh, et al. 2017 yang menyebutkan penggunaan golongan CCB yaitu amlodipin pada pasien hipertensi dapat menyebabkan edema parifer [8].

Hasil penelitian pada tabel 4, menunjukan bahwa amlodipin sebanyak 234 resep, dengan presentase 95,51\%, sedangkan captopril sebanyak 9 resep dengan presentase 3,67\%. Terapi kombinasi amlodipin dengan captopril sebanyak 2 resep dengan persentase $0,82 \%$.

Hasil analisis berdasarkan Peraturan Menteri Kesehatan No 67 Tahun 2015, menunjukan bahwa perlunya perhatian dari tenaga kesehatan termasuk dokter dan farmasis dalam penggunaan captopril dan amlodipin terapi tunggal atau terapi kombinasi pada lansia[14].

Tabel. 4 Peraturan Menteri Kesehatan No 67 Tahun 2015

\begin{tabular}{lcl}
\hline Jenis Obat & Jumlah R/ & Persentase \\
\hline Amlodipin & 234 & $95.51 \%$ \\
Captopriil & 9 & $3.67 \%$ \\
Amlodipin + Captopril & 2 & $0.82 \%$ \\
& & \\
\hline Total & 245 & $100 \%$
\end{tabular}

\section{Keterangan : \\ $\%$ Peresepan Obat $=\underline{\text { Jumlah R} /} \times \mathbf{~ 1 0 0 \%}$ \\ Jumlah Total $R /$}

\section{KESIMPULAN}

Pola peresepan obat diabetes melitus oral di Apotek Cahaya Husada Cilacap yaitu metformin sebanyak 47 resep (16,85\%), glimepirid sebanyak 38 resep (13,62\%). Terapi kombinasi obat diabetes melitus yaitu metformin dengan glimepirid sebanyak 136 resep $(48,75 \%)$. sPola peresepan obat hipertensi oral di Apotek Cahaya Husada Cilacap yaitu amlodipin 184 resep $(66,95 \%)$, irbesartan 10 resep $(3,58 \%)$, captopril 10 resep (3,58\%). Terapi kombinasi pada hipertensi terbanyak yaitu amlodipin dengan irbesartan sebanyak 18 resep $(6,45 \%)$, diikuti amlodipin dan candesartan sebanyak 13 resep (4,66\%), amlodipin dan telmisartan sebanyak 7 
resep $(2,51 \%)$. Obat-obat yang berpotensi menimbulkan ketidaktepatan penggunaan pada lansia berdasarkan kriteria beers 2019 yaitu glimepirid dan clonidin dengan terapi tunggal dan ganda. Glimepirid sebanyak 221 resep $(98,23 \%)$, clonidin sebanyak 2 resep $(0,89 \%)$, glibenklamid sebanyak 1 resep $(0,44 \%)$, terapi ganda glimepirid dengan clonidin sebanyak 1 resep $(0,44 \%)$.

\section{DAFTAR PUSTAKA}

[1] Kementerian PPN/ Bappenas, "Pedoman Pelaksanaan Intervensi Penurunan Stunting Terintegrasi di Kabupaten/Kota," Rencana Aksi Nas. dalam Rangka Penurunan Stunting Rembuk Stunting, 2018.

[2] A. S. Harti and D. Yuliana, "Pemeriksaan Rheumatoid Faktor Pada Penderita Tersangka Rheumatoid Arthritis," J. Kesehat. Kusuma Husada, vol. 3, no. 2, 2017, [Online]. Available: http://jurnal.ukh.ac.id/index.php/JK/article/view/34.

[3] D. R. Setyowati, Sudarso, and W. Utaminingrum, "Evaluasi Pola Peresepan Berdasarkan Beers Criteria Pada Pasien Geriatri Rawat Jalan pada Poli Penyakit Dalam di RSUD Prof. Dr. Margono Soekarjo Purwokerto Periode Agustus 2010-Maret 2011,” Pharmacy, 2011.

[4] E. Soviana and D. Maenasari, "Asupan Serat, Beban Glikemik Dan Kadar Glukosa Darah Pada Pasien Diabetes Melitus Tipe 2," J. Kesehat., 2019, doi: 10.23917/jk.v12i1.8936.

[5] D. Novrial, H. Sulistyo, and Setiawati, "Comparison of Antidiabetic Effects of Honey, Glibenclamide, Metformin and Their Combination In The Streptozotocin Induced Diabetics Rat," Semin. Nas. Kesehat. Jur. Kesehat. Masy. FKIK UNSOED, 2013.

[6] F. RI and Y. Wirawanni, "Asupan energi, karbohidrat, serat, beban glikemik, latihan jasmani dan kadar gula darah pada pasien diabetes melitus tipe 2," Pemberian Cairan Karbohidrat Elektrolit, Status Hidrasi dan Kelelahan pada Pekerja Wan., 2012.

[7] A. L. Hinderliter and R. E. Colindres, "Hipertensión," in Netter. Cardiología, 2006.

[8] F. Baroroh and A. Sari, "Analisis Efektivitas Biaya Pengobatan Kombinasi CandesartanAmlodipin Dibandingkan Dengan Kombinasi Candesartan-Diltiazem Pada Pasien Hipertensi Rawat Jalan," PHARMACY, 2017.

[9] R. Septiyana, H. S. Padmanegara, and S. Larasati, "Evaluasi Kerasionalan Peresepan Obat Anti Diabetes Militus Oral Pada Pasien Prolanis Bpjs Di Rumah Sakit Islam Kendal," J. Farmasetis, 2015, doi: 10.32583/FARMASETIS.V4I1.230.

[10] R. Yuswantina and N. Dyahariesti, "Analisis Efektivitas Biaya Penggunaan Antidiabetes Oral Tunggal dan Kombinasi Pada Pasien BPJS Penderita Diabetes Melitus Tipe 2 di Rumah Sakit X," Media Farm. Indones., vol. 13, no. 1, pp. 1340-1346, 2018, [Online]. Available: https://stifar.ac.id/ojs/index.php/MFI/article/view/47.

[11] D. M. Fick et al., "American Geriatrics Society 2019 Updated AGS Beers Criteria ${ }^{\circledR}$ for Potentially Inappropriate Medication Use in Older Adults," J. Am. Geriatr. Soc., 2019, doi: 10.1111/jgs.15767.

[12] T. Tonasih and H. Fajarini, "Pola penggunaan antihipertensi pada pasien rawat jalan di Puskesmas Siwuluh Kabupaten Brebes," J. Pharm. UMUS, vol. 01, no. 1, pp. 1-6, 2019, [Online]. Available: http://jurnal.umus.ac.id/index.php/jophus/article/view/45/28.

[13] N. B. Pangestu, M. D. Kurniasari, and A. T. Wibowo, "Efektifitas Yoga Ketawa terhadap Penurunan Tekanan Darah pada Lansia dengan Hipertensi Derajat II di Panti Wredha Salib Putih Salatiga," J. Kesehat., 2017, doi: 10.26630/jk.v8i3.650.

[14] Kementrian Kesehatan Indonesia, Peraturan Mentri Kesehatan Republik Indoensia Nomor 44 Tahun 2018 Tentang Penyelenggaraan Promosi Kesehatan Rumah Sakit. 2018. 